\title{
Pleiotropic Deficiency in the Control of Carbon-regulated Catabolic Enzymes in the 'Slime' Variant of Neurospora crassa
}

\author{
By ROSEMEIRE C. L. R. PIETRO, JOÃO A. JORGE AND \\ HÉCTOR F. TERENZI* \\ Departamento de Biologia, Faculdade de Filosofia, Ciências e Letras de Ribeirão Preto, \\ Universidade de São Paulo, 14.049 Ribeirão Preto, São Paulo, Brazil
}

(Received 26 October 1988; revised 14 December 1988; accepted 28 December 1988)

\begin{abstract}
A wall-less 'slime' strain of Neurospora crassa was shown to be pleiotropically altered in the production and secretion of several enzymes related to carbon catabolism, including invertase, alkaline protease, aryl- $\beta$-glucosidase and cellobiase. Invertase and protease were produced constitutively. The two $\beta$-glucosidases required induction by cellobiose but were poorly affected by glucose repression. Exoenzymes were released in larger amounts by the 'slime' strain than by the wild-type. Two other carbon-regulated enzymes, isocitrate lyase and phosphoenolpyruvate carboxykinase, were normally regulated in the 'slime' strain. A study of recombinants from a cross of a 'slime'-containing heterokaryon and wild-type suggested that the anomalies observed were inherent in the 'slime' phenotype.
\end{abstract}

\section{INTRODUCTION}

Neurospora crassa, like other filamentous fungi, can produce and secrete many different types of protein, in response to specific environmental stimuli such as nutrient limitation and presence of inducer substrates. The influence of the cell surface on the production of exported proteins has been known for several years. Fungal cells are surrounded by a complex interphase, the periplasmic compartment, delimited by the plasmalemma and the cell wall. Some proteins may be retained in this part of the cell, by covalent bonding to cell wall polymers (Kubicek, 1981; Lampen, 1971), by interaction with the plasma membrane, or by physical restraint due to the cell wall structure, which seems to act as a molecular sieve for proteins (Chang \& Trevithick, 1974; Kidby \& Davies, 1970; Trevithick \& Metzenberg, 1966). The pattern of synthesis and secretion of exoenzymes is frequently altered by mutations affecting cell wall structure and composition (Gratzner \& Sheenan, 1969; Gratzner, 1972; Murayama \& Ishikawa, 1973) as well as by the action of chemicals which cause the same effects (Mishra \& Tatum, 1972; Nanda et al., 1986; Sahoo et al., 1986; Silva \& Jorge, 1988). A radical condition of cell wall deficiency is present in the 'slime' variant of $N$. crassa (Emerson, 1963). This strain lacks entirely the cell wall structure, and therefore also lacks the periplasmic compartment. 'Slime' cultures develop as rounded, osmotically sensitive spheroplasts, which, unlike spheroplasts produced with lytic enzymes, can actively grow and multiply in solid or liquid medium (Trevithick \& Galsworthy, 1977). Because of these properties the 'slime' strain is an interesting system to study the influence of the cell wall and the periplasmic compartment on the control of protein secretion.

In comparison with the wild-type, 'slime' spheroplasts exhibit an abnormally high secretion of alkaline phosphatase (Burton \& Metzenberg, 1974) and invertase (Bigger et al., 1972). Casanova et al. (1987) demonstrated that invertase secretion in the 'slime' variant is resistant to glucose repression. We have now investigated the control of other carbon-regulated enzymes in the 'slime' variant, namely: the extracellular aryl- $\beta$-glucosidase $(\beta$-D-glucoside glucohydrolase, EC 3.2.1.21), alkaline protease, intracellular cellobiase (EC 3.2.1.21), isocitrate lyase (EC 4.1.3.1) and phosphoenolpyruvate carboxykinase (EC 4.1.1.38). We also studied the production of alkaline phosphatase (EC 3.1.3.1) and invertase (EC 3.2.1.26). 


\section{METHODS}

Neurospora strains and culture conditions. The following Neurospora crassa strains were used: FGSC $424 a$ (wildtype); FGSC 1118 (fz; sg;os-1; 'slime'), FGSC 2713 ( $f$; sg; arg- $1 ;$ cr- $1 ;$ al- $1 ;$ os $-1 ; A)+$ (tol; pan- $1 ; a)$ a 'slime'containing heterokaryon, and BAT 9-5 (cot-1; nic-3,a) an extra-fertile female parent (Cruz \& Terenzi, 1981) used for crosses. The first three strains were a gift from the Fungal Genetics Stock Center (Kansas City, Kansas, USA). Mycelial strains were propagated on slants of solid Vogel's (1956) medium with $2 \%(\mathrm{w} / \mathrm{v})$ sucrose and auxotrophy supplements when required. The 'slime' strain was maintained by weekly transfers on slants of solid Vogel's medium supplemented with $2 \%$ glucose, $0.75 \%$ Bacto-peptone (Difco) and $0.75 \%$ yeast extract (Difco). Liquid cultures were prepared in $250 \mathrm{ml}$ Erlenmeyer flasks containing $50 \mathrm{ml}$ Vogel's minimal medium supplemented with $2 \%$ glucose and $0.25 \mathrm{~m}$-sorbitol. Otherwise, medium composition is indicated for each experiment. The inoculum consisted of suspensions of macroconidia $\left(5 \times 10^{5} \mathrm{ml}^{-1}\right)$, or of 'slime' spheroplasts collected by suspending in $0.25 \mathrm{M}$-sorbitol the growth of a slant culture not more than $3 \mathrm{~d}$ old.

Liquid cultures were incubated with agitation ( 100 r.p.m.) at $30^{\circ} \mathrm{C}$. The 'slime' strain was usually grown for $48 \mathrm{~h}$ and mycelial strains for $17 \mathrm{~h}$. Thereafter the cultures were harvested by filtration (mycelial strains) or centrifugation at $159 \mathrm{~g}$ for $15 \mathrm{~min}$ ('slime' strains). Then, the samples were either transferred to fresh medium as indicated for each experiment, or processed for enzyme determination, when both the culture filtrates and supernatants were saved.

Enzyme determinations. 'Slime' spheroplasts, suspended in 10 vols of the appropriate buffer, were disintegrated by vortexing with $1.0 \mathrm{~g}$ of glass beads for two $90 \mathrm{~s}$ rounds, separated by an interval of cooling in ice. Mycelia were ground in a porcelain mortar with glass beads and extracted with 10 vols of the appropriate buffer. The supernatants of a low-speed centrifugation $(500 \mathrm{~g})$ and samples of culture media were dialysed overnight and used directly for enzyme determinations.

Aryl- $\beta$-glucosidase and cellobiase were estimated with $p$-nitrophenyl $\beta$-D-glucoside (Eberhart \& Beck, 1970). The amount of each enzyme relative to total $\beta$-glucosidase activity was estimated by thermal inactivation of cellobiase after incubating one of two paired samples for $1 \mathrm{~min}$ at $60^{\circ} \mathrm{C}$. One enzyme unit is defined as $1 \mathrm{nmol}$ p-nitrophenol released $\min ^{-1}$ at $30^{\circ} \mathrm{C}$. Invertase was determined according to Arnold (1974), using raffinose as a substrate; one enzyme unit is defined as the formation of $1 \mu \mathrm{mol}$ glucose (Miller, 1959) $\mathrm{min}^{-1}$ at $37^{\circ} \mathrm{C}$. Alkaline protease was assayed by spectrophotometric measurements of tyrosine released from casein (McDonald \& Chen, 1965; Drucker, 1972); one enzyme unit is defined as the colour equivalent of $1 \mu \mathrm{g}$ tyrosine $\min ^{-1}$ at $37^{\circ} \mathrm{C}$ (Hagihara et al., 1958). Isocitrate lyase and phosphoenolpyruvate carboxykinase activities were monitored in a Beckman DU-7 spectrophotometer (Dixon \& Kornberg, 1959; Flavell \& Fincham, 1968; respectively); one enzyme unit is defined as $1 \mu \mathrm{mol}$ product released $\min ^{-1}$ at $30^{\circ} \mathrm{C}$. The repressible alkaline phosphatase was assayed with $p$-nitrophenol phosphate (Burton \& Metzenberg, 1974); one enzyme unit is defined as $1 \mu \mathrm{mol}$ $p$-nitrophenol released $\min ^{-1}$ at $37^{\circ} \mathrm{C}$.

Specific activities were expressed as units per mg protein of crude cell extracts. Protein was determined by the Lowry method, using bovine serum albumin (Sigma) as standard.

Crosses. Crosses were performed according to standard procedures (Davis \& de Serres, 1970), using the strain BAT 9-5 as female parent and the heterokaryon FGSC 2713 as male parent, in standard Petri dishes on solid Westergaard \& Mitchell's (1947) crossing medium. Recombinants were isolated from plates of minimal Vogel's medium supplemented with $50 \mu \mathrm{g}$ nicotinic acid $\mathrm{ml}^{-1}, 100 \mu \mathrm{g}$ arginine $\mathrm{ml}^{-1}, 1 \%$ (w/v) sorbose, $0 \cdot 1 \%$ glucose, $0.1 \%$ fructose and $1.0 \mathrm{M}$-sorbitol. Germinated ascospores were transferred to slants of minimal Vogel's medium supplemented with sucrose, nicotinic acid and arginine. 'Slime-like' recombinants (Emerson, 1963) were submitted to a filtration-enrichment protocol (Nelson et al., 1975) by vegetative propagation in liquid medium of high osmolarity, in attempts to recover stable 'slime' phenotypes. Only in one of several trials was this operation successful (see Results).

Chemicals. $p$-Nitrophenyl $\beta$-D-glucoside, $p$-nitrophenyl phosphate, cellobiose, raffinose, sorbitol and sorbose were from Sigma. All other chemicals were analytical grade.

\section{RESULTS}

\section{$\beta$-Glucosidase activities in the wild-type and in 'slime' strain FGSC 1118}

Neurospora crassa produces two $\beta$-glucosidases: aryl- $\beta$-glucosidase, which is constitutive during conidiogenesis, and cellobiase. Neither enzyme is synthesized by exponentially growing vegetative mycelium, unless induced, cellobiose being the most effective inducer. Aryl- $\beta$ glucosidase is extracellular and accumulates preferentially on the surface of conidia. In contrast, cellobiase is intracellular (Eberhart \& Beck, 1970, 1973).

The two $\beta$-glucosidase activities were induced by cellobiose, in both wild-type and 'slime' cultures (Table 1). The basal (zero time) activities were somewhat higher in the 'slime' strain 
Table 1. $\beta$-Glucosidase specific activities in the wild-type and in the 'slime' strain FGSC 1118

The 'slime' strain was grown for $48 \mathrm{~h}$ at $30^{\circ} \mathrm{C}$, with agitation, in Vogel's medium supplemented with $2 \%$ glucose and $0.25 \mathrm{M}$-sorbitol. Wild-type cells were grown under the same conditions but only for $17 \mathrm{~h}$. At that time (zero time) the cultures were harvested by centrifugation ('slime') or filtration (wild-type) and resuspended in fresh Vogel's medium plus $0.25 \mathrm{M}$-sorbitol, with $2 \%$ glucose (repressed), $0.2 \%$ cellobiose (induced) or a mixture of both sugars at the same concentrations. After $8 \mathrm{~h}$ incubation at $30{ }^{\circ} \mathrm{C}$ the cultures were harvested and $\beta$-glucosidase activities were determined in the culture medium and cell extracts, as indicated in Methods. Specific activities (intracellular and extracellular) are expressed as units per $\mathrm{mg}$ of crude extracted protein.

\begin{tabular}{|c|c|c|c|c|c|c|c|c|}
\hline \multirow[b]{3}{*}{ Conditions } & \multicolumn{4}{|c|}{ Wild-type } & \multicolumn{4}{|c|}{ 'Slime' } \\
\hline & \multicolumn{2}{|c|}{ Aryl- $\beta$-gluc. } & \multicolumn{2}{|c|}{ Cellobiase } & \multicolumn{2}{|c|}{ Aryl- $\beta$-gluc. } & \multicolumn{2}{|c|}{ Cellobiase } \\
\hline & Intra & Extra & Intra & Extra & Intra & Extra & Intra & Extra \\
\hline Zero time & $1 \cdot 73$ & $0 \cdot 41$ & ND & ND & $2 \cdot 83$ & ND & $2 \cdot 70$ & ND \\
\hline Glucose & $1 \cdot 10$ & $0 \cdot 19$ & $1 \cdot 10$ & ND & $2 \cdot 84$ & ND & $3 \cdot 17$ & ND \\
\hline Cellobiose & $52 \cdot 30$ & $11 \cdot 40$ & $18 \cdot 50$ & 0.32 & $8 \cdot 00$ & $35 \cdot 54$ & $19 \cdot 30$ & $2 \cdot 75$ \\
\hline Cellobiose plus glucose & $2 \cdot 40$ & ND & $1 \cdot 33$ & ND & $5 \cdot 60$ & $3 \cdot 34$ & $15 \cdot 50$ & $2 \cdot 43$ \\
\hline No carbon source added & $4 \cdot 01$ & $1 \cdot 50$ & 0.69 & ND & $2 \cdot 83$ & ND & $2 \cdot 08$ & ND \\
\hline
\end{tabular}

ND, Not detected.

than in the wild-type, possibly because of the longer period of incubation required to grow the 'slime' strain. Nevertheless, the specific activities of induced 'slime' and wild-type cultures were similar. Induction by cellobiose was specific in both strains: other carbon sources tested such as galactose, maltose, trehalose and arabinose were ineffective or much less effective than cellobiose (not shown).

About $82 \%$ of the aryl- $\beta$-glucosidase produced by induced 'slime' cultures was secreted into the culture medium. In contrast, the wild-type secreted only $18 \%$. However, cellobiase activity was predominantly intracellular in both 'slime' and wild-type cultures. Some cellobiase activity was detected in the culture medium of the 'slime' strain, probably released from cells damaged during manipulation.

Glucose repression strongly affected the production of aryl- $\beta$-glucosidase and cellobiase in wild-type cultures but it was much less effective in the 'slime' strain. For instance, intracellular and extracellular aryl- $\beta$-glucosidase and (intracellular) cellobiase activities of 'slime' cultures incubated with glucose plus cellobiose were $70 \%, 9 \cdot 4 \%$ and $80.3 \%$ of the respective induced activity (plus cellobiose only). This result was strikingly different from that obtained with the wild-type, in which these values were $5 \%$ for intracellular aryl- $\beta$-glucosidase, negligible for the extracellular activity and $7 \cdot 2 \%$ for cellobiase.

\section{Invertase and alkaline protease activities in the wild-type and in 'slime' strain FGSC 1118}

Invertase and alkaline protease are carbon-controlled exoenzymes. Invertase synthesis can be induced by galactose and is repressed when glucose is present (Metzenberg, 1962) as shown for the wild-type in Table 2, where it can also be observed that about $72 \%$ of the induced invertase activity remained cell bound. These results are in agreement with those of other authors (Bigger et al., 1972; Metzenberg, 1963). In contrast, invertase appeared to be constitutive in the 'slime' strain, which in the absence of inducer produced four times more invertase per mg protein than did wild-type cultures. Addition of galactose did not increase the enzyme activity further. On the average, about $97 \%$ of the invertase activity produced by the 'slime' strain was extracellular.

Proteolytic activity is induced by proteins in combination with carbon, sulphur or nitrogen limitation (Drucker, 1972; Hanson \& Marzluf, 1975). The main component of the proteolytic system of $N$. crassa is an inducible, extracellular alkaline protease activity (Abbot \& Marzluf, 1984; Drucker, 1975). Table 3 shows the effect of a protein, gelatin, in cultures of the wild type and 'slime' strains. Alkaline protease activity of wild-type cultures incubated with gelatin was 13-fold and 25-fold higher in cells and external medium, respectively, than that of cultures incubated with glucose. Glucose strongly counteracted the inducing effect of gelatin. On the other hand, glucose-grown 'slime' cultures produced seven times more alkaline protease than 
Table 2. Invertase specific activities in the wild-type and in 'slime' strain FGSC 1118

Culture conditions were as described in the legend for Table 1 . Induced cultures were incubated for $15 \mathrm{~h}$ with $1.35 \%$ galactose. Invertase activity was determined as indicated in Methods. Specific activities (intracellular and extracellular) are expressed as units per $\mathrm{mg}$ of crude extracted protein.

\begin{tabular}{lrccrr}
\multicolumn{1}{c}{ Conditions } & $\overbrace{\text { Intra }}^{c}$ Wild-type & & \multicolumn{2}{c}{ 'Slime' } \\
Zero time & 1.72 & 0.15 & 0.37 & 7.07 \\
Glucose & 3.63 & 0.02 & 0.33 & 13.91 \\
Galactose & 16.11 & 6.38 & 0.55 & 18.48 \\
Galactose plus glucose & 4.36 & 0.44 & 0.40 & 20.85
\end{tabular}

Table 3. Alkaline protease specific activities in the wild-type and in the 'slime' strain FGSC 1118

Culture conditions were as described in the legend to Table 1. Induced cultures were incubated for $7 \mathrm{~h}$ with $0.25 \%$ gelatin. Alkaline protease activity was determined as described in Methods. Specific activities (intracellular and extracellular) are expressed as units per $\mathrm{mg}$ of crude extracted protein.

\begin{tabular}{|c|c|c|c|c|}
\hline \multirow[b]{2}{*}{ Conditions } & \multicolumn{2}{|c|}{ Wild-type } & \multicolumn{2}{|c|}{ 'Slime' } \\
\hline & Intra & Extra & Intra & Extra \\
\hline Zero time & $1 \cdot 13$ & $2 \cdot 82$ & $2 \cdot 63$ & $17 \cdot 41$ \\
\hline Glucose & 0.81 & 1.51 & $3 \cdot 37$ & 13.88 \\
\hline Gelatin & $10 \cdot 89$ & $38 \cdot 50$ & 1.72 & $21 \cdot 31$ \\
\hline Gelatin plus glucose & $2 \cdot 38$ & $9 \cdot 39$ & 3.73 & $17 \cdot 82$ \\
\hline
\end{tabular}

glucose-grown wild-type cultures, and the presence of gelatin did not alter this result. About $86 \%$ of the alkaline protease was extracellular in 'slime' cultures at zero time, as compared to $78 \%$ in induced wild-type cultures (Table 3).

\section{Phosphoenolpyruvate carboxykinase and isocitrate lyase activities in the wild-type and in 'slime' strain FGSC 1118}

To determine whether the 'slime' defects described above extended to other carbon-regulated enzymes, we examined phosphoenolpyruvate carboxykinase and isocitrate lyase activities. These are intracellular enzymes related to intermediary metabolism, which appear in low concentration in glucose-grown cells and become induced in the presence of gluconeogenic substrates such as acetate (Flavell \& Woodward, 1970). Phosphoenolpyruvate carboxykinase occurs in the cytosol, while isocitrate lyase is associated with glyoxysomes. As shown in Table 4, phosphoenolpyruvate carboxykinase and isocitrate lyase increased $4 \cdot 5$ - and 22 -fold respectively in wild-type cells induced by acetate, and this effect was counteracted by glucose. For the 'slime' strain, the induced levels of both enzymes were lower than those of the wild-type, but the two enzymes were evidently regulated in the 'slime' strain in the same way as in the wild-type.

Production of carbon-controlled exoenzymes in recombinants from a cross between the wild-type and a 'slime'-containing heterokaryon

Casanova et al. (1987) suggested that lack of glucose repression of invertase in a 'slime' variant is not related to the phenotypic absence of the cell wall. According to these authors, the invertase defect could be the result of an additional mutation, harboured by the 'slime' strain, different from those which determine the 'slime' wall-less phenotype. We investigated this possibility, using a genetic approach. A heterokaryon (FGSC 2713) containing 'slime' nuclei was used to fertilize wild-type 'female receptor' mycelium. Only the 'slime' component of the heterokaryon participated in the cross (Nelson et al., 1975). The heterokaryon itself exhibited normal production of exoenzymes. For instance, the two $\beta$-glucosidases, invertase and alkaline protease were inducible, and fully repressible by glucose. Furthermore, not more than $36 \%$ and $6.8 \%$ of 
Table 4. Phosphoenolpyruvate carboxykinase (PEPCK) and isocitrate lyase (ICL) specific activities in the wild-type and in the 'slime' strain FGSC 1118

Culture conditions were as described in the legend to Table 1 . Induced cultures were incubated for $6 \mathrm{~h}$ with $0.3 \%$ sodium acetate. Enzyme activities were determined in crude cell extracts as indicated in Methods. Specific activities are expressed as units per $\mathrm{mg}$ of crude extracted protein.

\begin{tabular}{lrrrr}
\multicolumn{1}{c}{ Conditions } & $\overbrace{\text { PEPCK }}^{\text {Wild-type }}$ & ICL & & \multicolumn{2}{c}{ 'Slime' } \\
Zero time & 39.00 & 8.90 & 11.56 & ICL \\
Glucose & 39.60 & 8.90 & 19.92 & 2.61 \\
Acetate & 178.40 & 194.80 & 38.68 & 46.32 \\
Acetate plus glucose & 40.00 & 10.00 & 20.39 & 6.80
\end{tabular}

aryl- $\beta$-glucosidase and invertase, respectively, were extracellular. Another enzyme which is secreted in excess by 'slime' strains, the repressible alkaline phosphatase (Burton \& Metzenberg, 1974), was $98 \%$ cell-bound in the heterokaryon. Thus, it seemed clear that the 'slime' phenotype behaved as recessive. Crosses produced abundant perithecia and ascospores. Germination was good (about 60-70\%), giving rise to non-osmotic and various classes of osmotic phenotypes, classified on the basis of morphology and sensitivity to high osmotic pressure (Perkins, 1959). Other phenotypes (i.e. abortive germination), as described by Emerson (1963), were also recognized. One percent or less of ascospores produced a plasmodioid outgrowth resulting in a very small colony of 'slime-like' cells. None of them maintained this characteristic, but developed mycelium after transfer to medium without sorbitol, or even in sorbitol solid medium after long periods of incubation. In an attempt to recover a stable 'slime' phenotype (i.e. producing spheroplasts regardless of osmotic concentration), ten such germinating ascospores were isolated, incubated in liquid medium of high osmolarity, and submitted to a filtrationenrichment procedure (Nelson et al., 1975). Only one stable 'slime' strain, designated S-4, was recovered. No attempt was made to characterize further the genotype of the recombinants with 'osmotic' phenotype obtained from the cross. Thus, the sample studied might contain other markers in addition to $o s-1$, which confers the osmotic-sensitive phenotype. The same might be true for the non-osmotic class selected.

Alkaline phosphatase secretion was not higher than $1-2 \%$ in any mycelial strain (non-osmotic and osmotic phenotypes), but was over $50 \%$ in the 'slime' recombinant S-4. In this respect S-4 behaved like the 'slime' strain studied by Burton \& Metzenberg (1974). Furthermore, $\beta$ glucosidase activities were normally regulated in all osmotic and non-osmotic strains, but not in the S-4 'slime' recombinant, in which the production of $\beta$-glucosidase activities was practically identical to that shown in Table 1 for the 'slime' strain FGSC 1118.

Intermediate phenotypes were observed for invertase and alkaline protease production (Table 5). Production and secretion of these exoenzymes exhibited a wild-type pattern in non-osmotic recombinants (compare with the data in Tables 2 and 3). The 'slime' strain S-4, like FGSC 1118 , produced the two enzymes constitutively and secreted large amounts of them into the culture medium. All osmotic recombinants exhibited an intermediate phenotype, characterized by partially constitutive levels of invertase and alkaline protease, incomplete glucose repression, and higher levels of secretion than the wild-type. This phenotype was not affected by culturing these strains in the presence or absence of sorbitol ( $1.0 \mathrm{M})$ (not shown).

\section{DISCUSSION}

The 'slime' strain of $N$. crassa was pleiotropically defective for the regulation of several carbon-catabolic enzymes, including invertase, alkaline protease, aryl- $\beta$-glucosidase and cellobiase. Invertase and alkaline protease were produced constitutively, and aryl- $\beta$-glucosidase and cellobiase, although inducible by cellobiose, were less sensitive than wild-type to carbon catabolite repression. In fact cellobiase synthesis in the 'slime' strain was almost fully resistant to 
Table 5. Invertase and alkaline protease activities in recombinants from a cross between the wild-type and a 'slime'-containing heterokaryon

Recombinants were obtained and scored as indicated in Methods. Culture conditions and other procedures were as indicated in the legends to Tables 2 and 3.

\begin{tabular}{|c|c|c|c|c|c|c|c|c|}
\hline \multirow[b]{3}{*}{ Phenotype } & \multicolumn{8}{|c|}{ Percentage specific activities* } \\
\hline & \multicolumn{4}{|c|}{ Invertase } & \multicolumn{4}{|c|}{ Alkaline protease } \\
\hline & A & B & $\mathrm{C}$ & $\mathrm{D}$ & A & B & $\mathrm{C}$ & D \\
\hline Non-osmotic & 4 & 5 & 3 & 14 & 56 & 79 & 4 & 23 \\
\hline Osmotic & 27 & 20 & 16 & 28 & 44 & 73 & 33 & 30 \\
\hline 'Slime' & 80 & 79 & 127 & 112 & 85 & 88 & 80 & 133 \\
\hline
\end{tabular}

* Figures represent relative percentage activities of the pooled results of seven independent isolates of nonosmotic and seven osmotic phenotypes, and one true 'slime' isolate. A, Extracellular activity in glucose-incubated cultures relative to total (extracellular plus intracellular) activity of the same cultures; B, extracellular activity in induced cultures relative to total activity of the same cultures; $C$, total activity in glucose-incubated cultures relative to total activity of induced cultures; $\mathrm{D}$, total activity in cultures incubated with glucose plus the inducer relative to total activity of cultures incubated with the inducer only.

glucose repression. Exoenzymes were released by the 'slime' cells in larger amounts than for the wild type. This was not an artifact due to the fragility of 'slime' cells because cellobiase, which is not an exportable protein, was normally retained in the cells. At least one other exoenzyme, alkaline phosphatase, is also secreted in large amounts by the 'slime' strains FGSC 1118 and S-4 studied here, and by at least one other (Burton \& Metzenberg, 1974).

The cause of these 'slime' defects is not clear. The observations performed using recombinants from a 'slime' $x$ wild-type cross did not reveal with certainty whether a mutation different from $o s-1, s g$ and $f z$, which are essential for the wall-less phenotype, was the cause of the abnormal regulation of catabolic enzymes. However, if the hypothetical mutation existed, it is clear that it could be only expressed in a stable, self-propagating, 'slime' phenotype.

The mechanism by which a stable 'slime' phenotype arises is rather puzzling. The very few ascospores from crosses with the 'slime' strain which germinated into plasmodioid outgrowth ('slime-like'; Emerson, 1963) invariably developed mycelium in media of normal osmolarity. In order to recover, rarely, a stable 'slime' phenotype, several cycles of vegetative propagation and enrichment in liquid and solid medium of high osmolarity are necessary (Nelson et al., 1975). Vegetative selection permits, occasionally, the derivation of clones which actively proliferate as pure spheroplasts regardless of osmolyte concentration (Emerson, 1963). Such phenotypic change involves drastic alterations in morphology, growth habit, cell-wall-organizing ability and several other characteristics. The mechanisms underlying this phenomenon are obscure and deserve more investigation. One possible explanation is that vegetative propagation selects secondary mutations influencing the conversion of 'slime-like' cells into stable 'slime' ones. However, this seems unlikely because Emerson (1963) demonstrated by genetic analysis that all essential mutations required for the expression of a stable 'slime' phenotype exist in 'slime-like' isolates. Furthermore, if other mutations different from $f z$, $s g$ and $o s-l$ determine the expression of 'slime', the inheritance of this phenotype in subsequent crosses should improve, but this has not been demonstrated (Emerson, 1963; authors' unpublished observations). No doubt the genetic basis of 'slime' would benefit from more investigation, for example of the $f z$ and $s g$ loci, which have not been mapped, or of the biochemical effects of $o s-1$.

The reason why phenotypic expression of 'slime' always requires a prolonged vegetative selection is not clear, but it might represent a gradual change occurring at the cell surface level, for instance, occasional loss of regulatory elements which participate in the expression of a number of cell functions such as organization of the cell wall, recognition of environmental signals, etc., which in 'slime' strains appear to be radically altered. 
This work was supported by grants from Financiadora de Estudos de Projetos (FINEP - PADCT) no. 44-84.0820-00 and Fundação de Amparo à Pesquisa do Estado de São Paulo (FAPESP) no. 87/0139-2. R.C.L.R.P. received a graduate (Doctoral) fellowship from Coordenadoria de Aperfeiçoamento de Pessoal de Ensino Superior (CAPES-BRASIL).

The work is part of a thesis submitted by R.C.L.R.P. to the Department of Biochemistry of the School of Medicine of Ribeirão Preto, University of São Paulo, in partial fulfilment of the requirement for the doctoral degree.

\section{REFERENCES}

Aвbot, R. J. \& MARzluf, G. A. (1984). Major extracellular protease of Neurospora crassa. Journal of Bacteriology 159, 505-510.

ARNOLD, W. N. (1974). Expression of cryptic $\beta$ fructofuranosidase in Saccharomyces rouxii. Journal of Bacteriology 120, 886-894.

Bigger, C. H., White, M. R. \& Braymer, H. D. (1972). Ultrastructure and invertase secretion of the slime mutant of Neurospora crassa. Journal of General Microbiology 71, 159-166.

Burton, E. G. \& Metzenberg, R. L. (1974). Properties of repressible alkaline phosphatase from wild type and a wall-less mutant of Neurospora crassa. Journal of Biological Chemistry 249, 46794688.

Casanova, A., Martinez, J. P., Gil, M. L., SentanDREU, R. \& Ruiz-HERrerA, J. (1987). Different molecular forms of invertase in the slime variant of Neurospora crassa: comparison with the wild-type strain. Journal of General Microbiology 133, 24472456.

Chang, P. L. Y. \& Trevithick, J. R. (1974). How important is secretion of exoenzymes through apical cell walls of fungi? Archives of Microbiology 101, 281293.

Cruz, A. K. \& Terenzi, H. F. (1981). Derepression of tyrosinase by sexual stimulation. Neurospora Newsletter 28, 8-10.

Davis, R. H. \& DE SERRES, F. J. (1970). Genetic and microbiological research techniques for Neurospora crassa. Methods in Enzymology 17A, 79-143.

Dixon, G. H. \& KornberG, H. L. (1959). Assay methods for key enzymes of the glyoxylate cycle. Biochemical Journal 72, 3P.

DRUCKER, H. (1972). Regulation of exocellular protease in Neurospora crassa: induction and repression of enzyme synthesis. Journal of Bacteriology 110, 1041-1049.

DRUCKER, H. (1975). Regulation of exocellular protease in Neurospora crassa: metabolic requirements of the process. Journal of Bacteriology 122, 11171125.

EBERHART, B. M. \& BECK, R. S. (1970). Localization of the $\beta$-glucosidases in Neurospora crassa. Journal of Bacteriology 101, 408-417.

EBERHART, B. M. \& BECK, R. S. (1973). Induction of the $\beta$-glucosidases in Neurospora crassa. Journal of Bacteriology 116, 295-303.

EMERSON, S. (1963). 'Slime'. A plasmodioid variant of Neurospora crassa. Genetica 34, 162-182.

Flavell, R. B. \& FinChaM, J. R. S. (1968). Acetatenonutilizing mutants of Neurospora crassa. II. Biochemical deficiencies and the roles of certain enzymes. Journal of Bacteriology 95, 10631068 .
Flavell, R. B. \& Woodward, D. O. (1970). The concurrent regulation of metabolically related enzymes. The Krebs cycle and glyoxylate shunt enzymes in Neurospora. European Journal of Biochemistry 17, 284-291.

GRATZNER, H. G. (1972). Cell wall alterations associated with the hyperproduction of extracellular enzymes in Neurospora crassa. Journal of Bacteriology 111, 443-446.

Gratzner, H. G. \& Sheenan, D. N. (1969). Neurospora mutant exhibiting hyperproduction of amylase and invertase. Journal of Bacteriology 97, 544-549.

Hagihara, B., Matsubara, H., Nakai, M. \& OkunUKI, L. (1958). Crystalline bacterial proteinase. I. Preparation of crystalline proteinase of Bacillus subtilis. Journal of Biochemistry 45, 185-194.

Hanson, M. A. \& Marzluf, G. A. (1975). Control of the synthesis of a single enzyme by multiple regulatory circuits in Neurospora crassa. Proceedings of the National Academy of Sciences of the United States of America 72, 1240-1244.

KidBy, D. K. \& Davies, R. (1970). Invertase and disulphide bridges in the yeast wall. Journal of General Microbiology 61, 327-333.

KuBICEK, C. P. (1981). Release of carboxymethylcellulase and $\beta$-glucosidase from cell walls of Trichoderma reesei. European Journal of Applied Microbiology and Biotechnology 13, 226-231.

LAMPEN, J. O. (1971). Yeast and Neurospora invertase. In The Enzymes, 3rd edn. vol. V, pp. 291-305. Edited by P. D. Boyer. New York: Academic Press.

McDonald, C. E. \& Chen, L. L. (1965). The Lowry modification in the Folin reagent of proteinase activity. Analytical Biochemistry 10, 175-177.

MetzenberG, R. L. (1962). A gene affecting the repression of invertase and trehalase in Neurospora. Archives of Biochemistry and Biophysics 96, 468-474.

MetzenberG, R. L. (1963). The localization of $\beta$ fructofuranosidase in Neurospora. Biochimica et biophysica acta 77, 455-465.

Miller, G. L. (1959). Use of dinitrosalicylic acid reagent for determination of reducing sugars. Analytical Biochemistry 31, 426-428.

Mishra, N. C. \& Tatum, E. L. (1972). Effect of Lsorbose on polysaccharide synthetases of Neurospora crassa. Proceedings of the National Academy of Sciences of the United States of America 69, 313-317.

Murayama, T. \& Ishikawa, T. (1973). Mutation in Neurospora crassa affecting some of the extracellular enzymes and several growth characteristics. Journal of Bacteriology 115, 796-804.

Nanda, M., Bisaria, V. S. \& Ghose, T. K. (1986). Effect of $\mathrm{L}(-)$ sorbose on cellulase activity in Trichoderma reesei QM 9414. Journal of General Microbiology 132, 3201-3207. 
Nelson, R. E., Littlewood, B. S. \& MetzenberG, R. L. (1975). Toward the domestication of slime. Neurospora Newsletter 22, 15-16.

PERKINS, D. D. (1959). New markers and multiple point linkage data in Neurospora. Genetics 44, 11851208.

Sahoo, D. K., Mishra, A. \& Bisaria, V. S. (1986). Influence of L-sorbose on growth and enzyme synthesis of Trichoderma reseei C-5. Journal of General Microbiology 132, 2761-2766.

SILVA, R. \& JORGE, J. A. (1988). The effects of sorbose on NAD(P)ase production by Aspergillus nidulans. Brazilian Journal of Medical and Biological Research 21, 735-745.

Trevithick, J. R. \& Galsworthy, P. R. (1977). Morphology of slime variants of Neurospora crassa growing on a glass surface in liquid medium. Archives of Microbiology 115, 109-118.

Trevithick, J. R. \& MetzenberG, R. L. (1966). Molecular sieving by Neurospora cell walls during secretion of invertase isozymes. Journal of Bacterio$\log y$ 92, 1010-1015.

VoGEL, H. J. (1956). A convenient growth medium for Neurospora (medium N). Microbial Genetics Bulletin 13, 42-43.

WestergaARD, M. \& Mitchell, H. K. (1947). Neurospora. V. A synthetic medium favoring sexual reproduction. American Journal of Botany 34, 573577. 